\title{
Incidence and predictors of chronic kidney diseases among type 2 diabetes mellitus patients at St. Paul's Hospital, Addis Ababa, Ethiopia
}

\author{
Alemayehu Hussen Geletu', Alemayehu Shimeka Teferra ${ }^{2}$, Malede Mequanent Sisay ${ }^{2 *}$ \\ and Destaw Fetene Teshome ${ }^{2}$
}

\begin{abstract}
Objective: This study aimed to estimate the incidence of chronic kidney disease and its predictors among newly diagnosed type 2 diabetes patients attending St. Paul's Hospital, Addis Ababa, Ethiopia.

Results: The overall incidence of chronic kidney disease was a major public health issue among type 2 diabetes mellitus patients with 2178 (95\% Cl 12,801,21,286) cases per 10,000 patient-months. Moreover, 62(14.25\%) patients in the sample experienced chronic kidney disease. Old age [adjusted hazard ratio (AHR) $=1.06,95 \% \mathrm{Cl} 1.03,1.09]$, no diabetic retinopathy $[A H R=0.13,95 \% \mathrm{Cl} 0.07-0.24]$, high density lipoprotein cholesterol $\geq 40 \mathrm{mg} / \mathrm{dl}[\mathrm{AHR}=0.55,95 \% \mathrm{Cl} 0.31$, $0.97]$ and high body mass index $[\mathrm{AHR}=1.17,95 \% \mathrm{Cl} 1.1,1.25]$ were common factors for chronic kidney diseases.
\end{abstract}

Keywords: Chronic kidney diseases, Type 2 diabetes, Diabetic complications, Predictors

\section{Introduction}

Chronic kidney disease contributes substantially to human suffering and death [1]. For instance, the estimated prevalence of people who have experienced CKD is $11-13 \%$ and $13.9 \%$ worldwide and sub-Saharan Africa respectively. chronic kidney disease is a critical issue in the management of patients with type 2 diabetes mellitus [1-5].

Previous studies in the area indicated that is mainly driven by diabetic mellitus (DM). For example, type 2 diabetes mellitus (T2DM) causes $30-50 \%$ of CKD cases [6-10]. According to recent literature, CKD is more prevalent (11-29\%) are among type 2 diabetic patients in developed than in developing countries [11-13]. A similar h study done in Hong Kong and South Africa reported a development of CKD among type 2 DM patients at a

\footnotetext{
*Correspondence: maledecsa@gmail.com

2 Department of Epidemiology and Biostatistics, Institute of Public Health, College of Medicine and Health Sciences, University of Gondar, 196, Gondar, Ethiopia

Full list of author information is available at the end of the article
}

rate of 12.7 and $94.9 \%$, respectively [14, 15]. Although the prevalence of CKD ranged from 2 to $41 \%$ in Africa $[5,16]$, the growing burden of CKD among type $2 \mathrm{DM}$ patients is not well explored in low and middle-income countries [17-20].

Several studies highlighted the risk factors for CKD complication of type 2 diabetic patients. For example, age and sex were significant risk factors for CKD in type 2 diabetic patients [21-23]. However, studies found disparities in the risk factors for chronic kidney diseases [13, 22, 24-26]. In another cohort study, physical activity reduces the incidence [21], whereas smoking history and lipid abnormalities have increased the risk of CKD in type 2 DM patients [12, 27-31]. In another prospective study done among type 2 diabetic patients, factors such as high systolic blood pressure (SBP), low diastolic blood pressure (DBP) and high body mass index (BMI) significantly affected the CKD [12, 29, 32, 33]. Moreover, hypoglycemia, history of hypertension and diabetic retinopathy were considerable risks [5, 12, 22, 34-36]. A systematic review and meta-analysis revealed that BP 
lowering medications and intensive blood-glucose control can reduce the risk of CKD [37, 38].

Previous studies showed that the incidence of diabetic kidney disease varied across countries. But this emerging global public health problem is not well investigated, rather it is overlooked in low-come countries including Ethiopia. Quantifying the burden of the disease and early detection of the risk factors is paramount in the prevention of CKD. Therefore, this study aimed to estimate the incidence of chronic kidney disease and its predictors among newly diagnosed type 2 diabetes patients attending St. Paul's Hospital, Addis Ababa, Ethiopia.

\section{Main text \\ Methods}

An institution-based retrospective follow-up study was conducted at St. Paul's Hospital, Addis Ababa, Ethiopia. St. Paul's Referral Hospital is found in the capital of Ethiopia, Addis Ababa. Since 1969 the hospital has been providing different medical care services included chronic problems like chronic kidney disease and supports to an estimated 200,000 people annually referred from all over the country.

All newly diagnosed T2DM patients who enrolled at St. Paul's Referral Hospital between January 2008 and November 2017 were considered in this study. The required sample (435) was determined by the incidence and predictors of CKD using STATA software. New T2DM diagnosed patients were eligible, while those who had CKD at the time of the diagnosis for T2DM were excluded from the study.

The data were collected using a standard extraction checklist which was adapted from the World Health Organization (WHO) guidelines [39]. After they were checked for completeness, data were entered using Epi Info 7 and exported to STATA 12 for further analysis. The outcome variable in this study was time to chronic kidney disease. Chronic kidney disease was defined as an estimated Glomerular Filtration Rate (eGFR) $<60 \mathrm{ml} /$ $\mathrm{min} / 1.73 \mathrm{~m}^{2}$ estimated by the Cockcroft-Gault equation. Accordingly, participants were classified as either CKD cases or censored at the end of the study. Furthermore, the incidence of CKD was determined from the start of type $2 \mathrm{DM}$ diagnosis until the last follow-up visit.

We used the Weibull Cox regression models to identify the predictors. Variables in the bi-variable proportional hazard model with a P-value below 0.2 were included in the multivariable analysis. For the overall model, Scaled Schoenfeld and Cox-Snell residuals plots were used to check the assumption. The most parsimonious model was chosen by Akaike's Information Criterion (AIC). Finally, the crude and adjusted hazard ratio (HR) with its 95\% CI was calculated to determine statistical significance.

\section{Results}

A total of 435 newly diagnosed T2DM patients were included in this study. Approximately half (50.6\%) were females and only $101(23.2 \%)$ treated with insulin. More than half, 235(54\%) had a history of hypertension, 404 (92.9\%) had no history of diabetic retinopathy, and 261(66\%) had a baseline LDL cholesterol level below $100 \mathrm{mg} / \mathrm{dl}$. Slightly more than half (50.5\%) of the patients had less than $40 \mathrm{mg} / \mathrm{dl}$ HDL cholesterol level. Similarly, $225(56.4 \%)$ had triglyceride level greater or equal to $150 \mathrm{mg} / \mathrm{dl}$ and 259(64.6\%) had less than $200 \mathrm{mg} / \mathrm{dl}$ total cholesterol level [Table 1].

The median time to develop CKD was 70.9 months with an interquartile range of (IQR: 41.00-88.73 months). The overall incidence rate of CKD was 2178 (95\% CI $12,801,21,286)$ cases per 10,000 patient-month with total 28,466.13 patient-months observation. Moreover, the proportion of CKD among newly diagnosed T2DM patients was $14.25 \%$.

The Kaplan-Meir curve showed that the chance of developing CKD for a patient who has T2DM increased over time. A large number of CKD diagnosed T2DM patients were observed between 60 and 80 months of the study period [Additional file 1]. Furthermore, a comparison of the survival functions of patients who had diabetic retinopathy complications showed a shorter CKD complication time than patients who didn't have (log-rank $\left.X^{2}=67.4, \quad \mathrm{P}<0.0001\right)$. Survival differences were also

Table 1 Baseline factors of newly diagnosed T2DM patients in St. Paul's Hospital, Addis Ababa, from January 2008 to April 2017

\begin{tabular}{llll}
\hline Variables & Categories & Frequency & Percent \\
\hline Sex & Male & 215 & 49.4 \\
& Female & 220 & 50.6 \\
Types of DM therapy & Insulin & 101 & 23.2 \\
& Oral & 334 & 76.8 \\
History of hypertension & No & 198 & 45.5 \\
Anti-hypertensive therapy & Yes & 237 & 54.5 \\
History of diabetic retinopathy & No & 251 & 57.7 \\
& Yes & 184 & 42.3 \\
LDL cholesterol, mg/dl & $<100$ & 261 & 92.9 \\
& $\geq 100$ & 135 & 7.1 \\
HDL cholesterol, mg/dl & $<40$ & 200 & 34.0 \\
& $\geq 40$ & 196 & 50.5 \\
Total cholesterol, mg/dl & $<200$ & 259 & 49.5 \\
Triglyceride, mg/dl & $\geq 200$ & 142 & 34.6 \\
& $<150$ & 174 & 43.6 \\
& & 225 & 56.4 \\
\hline
\end{tabular}


observed in patients who had HDL Cholesterol level (log$\operatorname{rank} X^{2}=14.07, \mathrm{P}<0.0001$ ).

Based on AIC, Weibull Cox regression model was the most efficient model to describe the data $(\mathrm{AIC}=243.2)$. According to the Schoenfeld residual global test, the overall full model satisfies the proportional hazard assumption $\left(X^{2}=6.04, \mathrm{P}<0.481\right)$. As well, the Cox Snell residual plot showed the proportional hazard assumption was satisfied (Fig. 1).

In multivariable, the Weibull Cox regression, age, history of diabetic retinopathy, high HDL cholesterol and BMI were significantly associated with the likelihood of CKD among type 2 diabetic patients.

The risk of developing CKD among newly diagnosed T2DM patients rose by $6 \%$ with a 1 -year increase in age $[\mathrm{AHR}=1.06,95 \% \mathrm{CI} 1.03-1.09]$. The risk of developing CKD decreased by $87 \%$ [AHR $=0.13,95 \%$ CI $0.07-0.24$ ] among newly diagnosed T2DM with no history of diabetic retinopathy than patients with diabetic retinopathy. The risk of developing CKD decreased by $45 \%$ among newly diagnosed type 2 diabetic patients with high HDL cholesterol level $(\geq 40 \mathrm{mg} / \mathrm{dl})$ than patients with low HDL cholesterol level $[\mathrm{AHR}=0.55,95 \%$ CI 0.31 0.97]. Furthermore, for a unit increase in BMI, the hazard of developing CKD among newly diagnosed T2DM patients increases by $17 \%$ [AHR $=1.17,95 \%$ CI $1.1-1.25$ ] [Table 2].

\section{Discussion}

This study investigated the incidence and predictors of chronic kidney disease among newly diagnosed T2DM patients at St. Paul's Hospital, Addis Ababa, Ethiopia.

In the study, the cumulative incidence of CKD was 2178 (95\% CI 12,801, 21,286) cases per 10,000

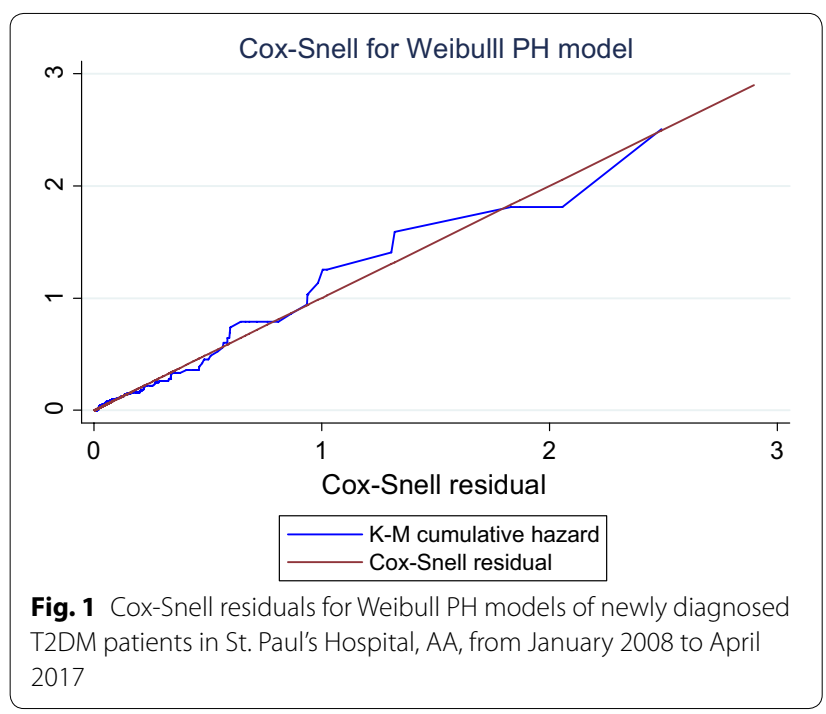

patient-months. This study revealed a higher incidence of CKD than the studies done in Hong Kong [14], Italy [11], Sweden [13] and Spain [35]. The differences could be attributed to the short follow up time used by the other studies and the variations in diagnostic methods applied. Moreover, the black race was associated with a greater rate of GFR decline which increases the incidence of CKD [40]. However, it was lower than that of a study done in UK [12]. This could be due to the difference in the study design used by the U.K, which was a prospective follow up study.

In this study, we have found that age is a risk factor for CKD. The finding is consistent with those of studies conducted in U.K [12], Taiwan [21], Japan [22], and Italy [41]. This might be because getting older age is associated with such risk factors CKD as cardiovascular diseases and obesity as well as endothelial cell dysfunction, activation of the sympathetic nervous system which promotes glomerulonephritis and chronic renal failure [42, 43]. This makes the mean change in eGFR decline with increases in age [44].

Patients with high BMI were significantly associated with CKD. The finding is inconsistent with those of studies conducted in Sweden [13], Italy [30, 45] and Israel [46]. The possible reason could be that an increased BMI promotes kidney damage through direct mechanisms like hemodynamic and hormonal effects. This might also lead to glomerular hyper fusion and glomerular hyper filteration; as a result, glomerular capillary pressure increases which may subsequently result in an increased urinary albumin excretion, followed by overt proteinuria and declining GFR [47]. Weight loss intervention is assistant for medical treatments to prevent or delay the progression of CKD in overweight or obese people with type 2 diabetes [48].

This study found that the presence of diabetic retinopathy at baseline was a high risk for CKD. This finding is in line with those studies conducted in Japan [22] and UK [12]. This might be associated with the elevation of cardiac biomarkers and endothelial dysfunction which in turn lead to circulatory abnormalities increases proteinuria and reduces vascular reactivity that reflects systemic factors associated with the development of CKD $[49,50]$.

In this study, we found that higher levels of HDL cholesterol $(\geq 40 \mathrm{mg} / \mathrm{dl})$ were associated with a lower risk for CKD. This result was in concordance with those of studies conducted in Italy [30] and Japan [22]. Biologically, HDL cholesterol may be protective against the incidence of CKD. Moreover, type 2 diabetes patients might be primarily involved in the reverse cholesterol transport and in a number of other non-cholesterol dependent effects, including anti-oxidant, anti-inflammatory, anti-thrombotic and vasopressin effects. All of these beneficial 
Table 2 Multivariable analysis of Weibull PH model for newly diagnosed T2DM patients in St. Paul's Hospital, AA, from January 2008 to April 2017

\begin{tabular}{|c|c|c|c|c|c|}
\hline \multirow[t]{2}{*}{ Variables } & \multirow[t]{2}{*}{ Category } & \multicolumn{2}{|c|}{ CKD status } & \multirow[t]{2}{*}{ Crude HR $[95 \% \mathrm{Cl}]$} & \multirow[t]{2}{*}{ Adjusted HR $[95 \% \mathrm{Cl}]$} \\
\hline & & Censored & Event & & \\
\hline \multirow[t]{2}{*}{ Sex } & Male & 185 & 30 & 1 & \\
\hline & Female & 188 & 32 & $0.94(0.57,1.54)$ & \\
\hline \multicolumn{4}{|l|}{ Age } & $1.07(1.04,1.09)$ & $1.06(1.03,1.09)^{*}$ \\
\hline \multirow[t]{2}{*}{ Diabetic retinopathy } & Yes & 357 & 47 & 1 & 1 \\
\hline & No & 16 & 15 & $0.11(0.06,0.2)$ & $0.13(0.07,0.24)^{*}$ \\
\hline \multirow[t]{2}{*}{ History of hypertension } & No & 174 & 26 & 1 & \\
\hline & Yes & 199 & 36 & $1.18(0.71,1.95)$ & \\
\hline \multirow[t]{2}{*}{ Hypertensive therapy } & No & 213 & 38 & 1 & \\
\hline & Yes & 160 & 24 & $0.83(0.5,1.4)$ & \\
\hline \multirow[t]{2}{*}{ Types of DM therapy } & Insulin & 85 & 16 & 1 & \\
\hline & Oral & 288 & 46 & $0.96(0.54,1.7)$ & \\
\hline \multicolumn{4}{|l|}{$\mathrm{FBG}(\mathrm{mg} / \mathrm{dl})$} & $0.99(0.995,1.002)$ & \\
\hline \multicolumn{4}{|l|}{ SBP (mmHg) } & $1.02(1.01,1.03)$ & \\
\hline \multicolumn{4}{|l|}{$\mathrm{DBP}(\mathrm{mmHg})$} & $1.03(1.01,1.05)$ & \\
\hline \multirow[t]{2}{*}{ LDL cholesterol } & $<100 \mathrm{mg} / \mathrm{dl}$ & 221 & 40 & 1 & \\
\hline & $\geq 100 \mathrm{mg} / \mathrm{dl}$ & 113 & 22 & $1.02(0.61,1.72)$ & \\
\hline \multirow[t]{2}{*}{ HDL cholesterol } & $<40$ mg/dl & 155 & 45 & 1 & 1 \\
\hline & $\geq 40 \mathrm{mg} / \mathrm{dl}$ & 179 & 17 & $0.35(0.2,0.62)$ & $0.55(0.31,0.97)^{*}$ \\
\hline \multirow[t]{2}{*}{ Total cholesterol } & $<200 \mathrm{mg} / \mathrm{dl}$ & 221 & 38 & 1 & \\
\hline & $\geq 200 \mathrm{mg} / \mathrm{dl}$ & 118 & 24 & $1.09(0.65,1.8)$ & \\
\hline \multirow[t]{2}{*}{ Triglyceride } & $<150 \mathrm{mg} / \mathrm{dl}$ & 221 & 38 & 1 & \\
\hline & $\geq 150 \mathrm{mg} / \mathrm{dl}$ & 118 & 24 & $1.35(0.81,2.25)$ & \\
\hline \multicolumn{4}{|c|}{$\mathrm{BMI}(\mathrm{kg} / \mathrm{m} 2)$} & $1.2(1.1,1.3)^{*}$ & $1.17(1.1,1.25)^{*}$ \\
\hline \multicolumn{5}{|c|}{ LR test $X^{2}(6)=96.7, P>X^{2}=0.0000$, Log likelihood $=-113.6$} & $\mathrm{AIC}=243.2$ \\
\hline
\end{tabular}

*P-value $<0.05$

vascular effects may also act to explain the lower risk of CKD incidence [30].

\section{Conclusion}

In this study, the incidence of CKD among type $2 \mathrm{DM}$ patients was moderately growing burdens and seek public concerns. Old age, high BMI, history of diabetic retinopathy and lower levels of HDL cholesterol were risk factors for the development of CKD. More attention and close monitoring should be exercised in order to control high BMI, high HDL cholesterol and diabetic retinopathy among the elderly.

\section{Limitations}

This investigation attempted to estimate the incidence of CKD and identify risk factors for the disease which may serve as input for policy and program designing in the context of a developing country. Indeed, this study included only type 2 diabetic patients who attended the hospital. Selection bias might have occurred if patients lived at home undiagnosed during the time.
Additionally, the research did not investigate the behavioral and institutional characteristics because they were not available in the hospital records, making it difficult to assess possible confounders. Therefore, the findings should be interpreted with this limitation in mind.

\section{Additional file}

Additional file 1. Kaplan-Meier cumulative hazard estimate of newly diagnosed T2DM patients at St. Paul's Hospital, Ethiopia.

\section{Abbreviations}

AHR: adjusted hazard ratio; AIC: Akaike information criteria; BMI: body mass index; CKD: chronic kidney disease; DM: diabetes mellitus; HDL: high-density lipoprotein; T2DM: type 2 diabetes mellitus; WHO: World Health Organization.

\section{Authors' contributions}

All authors equally participated in the design, conception, analysis, and interpretation. AHG facilitated the data collection and drafted. MMS, AST, and DFT made critical revision the manuscript for important intellectual content. All had full access to all of the data in the study and takes responsibility for the integrity of the data and the accuracy of the data analysis. All authors read and approved the final manuscript. 


\begin{abstract}
Author details
${ }^{1}$ Department of Reproductive Health, School of Public Health, College of Medicine and Health Sciences, Addis Ababa University, Addis Ababa, Ethiopia. ${ }^{2}$ Department of Epidemiology and Biostatistics, Institute of Public Health, College of Medicine and Health Sciences, University of Gondar, 196, Gondar, Ethiopia.
\end{abstract}

\section{Acknowledgements}

The authors express their appreciation to St. Paul's specialized referral hospital, particularly the DM clinic staff for their kind cooperation during data collection. The authors are grateful to data collectors too.

\section{Competing interest}

The authors declare that they have no competing interest.

\section{Availability of data and materials}

All relevant data are in the manuscript. However, the minimal data underlying all the findings in the manuscript will be available upon request.

\section{Consent for Publication}

Not applicable.

\section{Ethics approval and consent to participate}

Ethical clearance and approval were obtained from an ethical review committee of the Institute of Public health, College of Medicine and Health Science, University of Gondar. Permission letter also obtained from a chief clinical officer of St. Paul's hospital to review and use medical records of the study participants. Confidentiality of the patients was maintained through identification number rather than names, and questionnaires kept safe throughout.

\section{Funding}

The authors disclose that did not receipt any fund for this research, and publication of this article. This research was self-sponsored.

\section{Publisher's Note}

Springer Nature remains neutral with regard to jurisdictional claims in published maps and institutional affiliations.

Received: 14 May 2018 Accepted: 19 July 2018

Published online: 31 July 2018

\section{References}

1. Jha V, et al. Chronic kidney disease: global dimension and perspectives. Lancet. 2013;382(9888):260-72.

2. Lozano R, et al. Global and regional mortality from 235 causes of death for 20 age groups in 1990 and 2010: a systematic analysis for the Global Burden of Disease Study 2010. Lancet. 2010;380(9859):2095-128.

3. Hill NR, et al. Global prevalence of chronic kidney disease-a systematic review and meta-analysis. PLOS ONE. 2016;11(7):e0158765.

4. Stanifer JW, et al. The epidemiology of chronic kidney disease in subSaharan Africa: a systematic review and meta-analysis. Lancet Glob Health. 2014;2(3):e174-81.

5. ElHafeez SA, et al. Prevalence and burden of chronic kidney disease among the general population and high-risk groups in Africa: a systematic review. BMJ Open. 2018;8:e015069.

6. IDF, Global guideline for type 2 diabetes. 2012.

7. WHO. Global report on diabetes. Geneva: WHO; 2016.

8. IDF, Diabetes Atlas. 7th ed; 2015.

9. Jha $\mathrm{V}$, Wang $A Y$, Wang $H$. The impact of CKD identification in large countries: the burden of illness. Nephrol Dial Transplant. 2012;27(Suppl 3):iii32-8.

10. Reutens AT. Epidemiology of diabetic kidney disease. Med Clin North Am. 2013;97(1):1-18.

11. Zoppini $G$, et al. Serum uric acid levels and incident chronic kidney disease in patients with type 2 diabetes and preserved kidney function. Diabetes Care. 2012;35(1):99-104.

12. Retnakaran $\mathrm{R}$, et al. Risk factors for renal dysfunction in type 2 diabetes: U.K. Prospective Diabetes Study 74. Diabetes. 2006:55(6):1832-9.
13. Afghahi $\mathrm{H}$, et al. Risk factors for the development of albuminuria and renal impairment in type 2 diabetes-the Swedish National Diabetes Register (NDR). Nephrol Dial Transplant. 2011;26(4):1236-43.

14. Luk $A O$, et al. Metabolic syndrome predicts new onset of chronic kidney disease in 5829 patients with type 2 diabetes: a 5-year prospective analysis of the Hong Kong Diabetes Registry. Diabetes Care. 2008:31(12):2357-61

15. Keeton GR, Smit RV, Bryer A. Renal outcome of type 2 diabetes in South Africa-a 12-year follow-up study. S Afr Med J. 2004:94(9):771-5.

16. Stanifer JW, et al. The epidemiology of chronic kidney disease in subSaharan Africa: a systematic review and meta-analysis. Lancet Glob Health. 2014;2:e174-81.

17. Thomas MC, Cooper ME, Zimmet P. Changing epidemiology of type 2 diabetes mellitus and associated chronic kidney disease. Nat Rev Nephrol. 2016;12(2):73-81.

18. Naicker S. End-stage renal disease in sub-Saharan Africa. Kidney Int Suppl. 2013;3:161-3

19. Amos AF, McCarty DJ, Zimmet P. The rising global burden of diabetes and its complications: estimates and projections to the year 2010. Diabet Med. 1997:14(Suppl 5):S1-85.

20. Parving $\mathrm{HH}$, et al. Prevalence and risk factors for microalbuminuria in a referred cohort of type II diabetic patients: a global perspective. Kidney Int. 2006;69(11):2057-63.

21. Lina $\mathrm{HC}$, et al. Physical activity is associated with decreased incidence of chronic kidney disease in type 2 diabetes patients: A retrospective cohort study in Taiwan. Care Diab. 2014;8:315-21.

22. Takagi M, Babazono T, Uchigata Y. Differences in risk factors for the onset of albuminuria and decrease in glomerular filtration rate in people with type 2 diabetes mellitus: implications for the pathogenesis of diabetic kidney disease. Diabet Med. 2015;32(10):1354-60.

23. Krakoff J, et al. Incidence of retinopathy and nephropathy in youthonset compared with adult-onset type 2 diabetes. Diabetes Care. 2003;26(1):76-81.

24. Gall MA, et al. Risk factors for development of incipient and overt diabetic nephropathy in patients with non-insulin dependent diabetes mellitus: prospective, observational study. BMJ. 1997:314(7083):783-8.

25. Hauteclocque $A D$, et al. The influence of sex on renal function decline in people with Type 2 diabetes. Diabet Med. 2014;31:1121-8.

26. Margaret KY, Wayne K, Bessie AY. Associations between sex and inciden chronic kidney disease in a prospective diabetic cohort. Nephrology. 2015;20:451-8

27. Mehler $S$, et al. Smoking as a risk factor for nephropathy in non-insulindependent diabetics. J Gen Intern Med. 1998;13:842-5.

28. Paul $M$, et al. Plasma lipids and risk of developing renal dysfunction: the atherosclerosis risk in communities study. Kidney Int. 2000;58:293-301.

29. Ravid M, et al. Main risk factors for nephropathy in type 2 diabetes mellitus are plasma cholesterol levels, mean blood pressure, and hyperglycemia. Arch Intern Med. 1998;158(9):998-1004

30. Zoppini $\mathrm{G}$, et al. Higher HDL cholesterol levels are associated with a lower incidence of chronic kidney disease in patients with type 2 diabetes. Nut Metab Cardiovasc Dis. 2009:19(8):580-6.

31. Bash LD, et al. Poor glycemic control in diabetes and the risk of incident chronic kidney disease even in the absence of albuminuria and retinopathy. Arch Intern Med. 2008;168(22):2440-7.

32. Bakris $\mathrm{GL}$, et al. Effects of blood pressure level on progression of diabetic nephropathy. Arch Intern Med. 2003;163:11.

33. Ridderstra $M$, et al. Obesity and cardiovascular risk factors in type 2 diabetes: results from the Swedish National Diabetes Register. J Intern Med. 2006;259:314-22

34. Shih CJ, et al. Association of hypoglycemia with incident chronic kidney disease in patients with type 2 diabetes: a nationwide population-based study. Medicine. 2015:94(16):e771.

35. Salinero-Fort MA, et al. Five-year incidence of chronic kidney disease (stage 3-5) and associated risk factors in a Spanish cohort: the MADIABETES Study. PLoS ONE. 2015;10(4):e0122030

36. Strippoli GF, Craig M, Craig JC. Antihypertensive agents for preventing diabetic kidney disease. Cochrane Database Syst Rev. 2005;19(4):CD004136.

37. Emdin Connor A, et al. Blood pressure lowering in type 2 diabetes: a systematic review and meta-analysis. JAMA. 2015;313(6):13. 
38. UKPD. Intensive blood-glucose control with sulphonylureas or insulin compared with conventional treatment and risk of complications in patients with type 2 diabetes (UKPDS 33). UK Prospective Diabetes Study (UKPDS) Group. Lancet. 1998;352(9131):837-53.

39. WHO. Guidelines for the prevention, management and care of diabetes mellitus; 2006. p. 32.

40. Hunsicker $L G$, et al. Predictors of the progression of renal disease in the Modification of Diet in Renal Disease Study. Kidney Int. 1997;51:12.

41. Targher $\mathrm{G}$, et al. Increased risk of CKD among type 2 diabetics with nonalcoholic fatty liver disease. J Am Soc Nephrol. 2008;19:1564-70.

42. Jessica JR, Anderson S. The aging kidney: physiological changes. Adv Chronic Kidney Dis. 2010;17(4):6.

43. Barton M. Ageing as a determinant of renal and vascular disease: role of endothelial factors. Nephrol Dial Transplant. 2005;20:6.

44. Eriksen $\mathrm{BO}$, Ingebretsen $\mathrm{OC}$. The progression of chronic kidney disease: $\mathrm{A}$ 10-year population-based study of the effects of gender and age. Kidney Int Suppl. 2006;69(8):375.
45. Bruno $G$, et al. Low incidence of end-stage renal disease and chronic renal failure in type 2 diabetes. Diabetes Care. 2003;26:2353-8.

46. Asaf $\mathrm{V}$, et al. Body mass index in 1.2 million adolescents and risk for endstage renal disease. Arch Intern Med. 2012;172:1644-50.

47. Garland JS. Elevated body mass index as a risk factor for chronic kidney disease: current perspectives. Auckland: Dove Medical Press; 2014. p. 9.

48. Knowler WC, et al. Effect of a long-term behavioral weight loss intervention on nephropathy in overweight or obese adults with type 2 diabetes: a secondary analysis of the Look AHEAD randomized clinical trial. Lancet Diabetes Endocrinol. 2014;2:801-9.

49. Juan EG, et al. Retinopathy and chronic kidney disease in the chronic renal insufficiency cohort study (CRIC). Arch Ophthalmol. 2012;130(9):9.

50. Yip W, Peng GO, et al. Retinal vascular imaging markers and incident chronic kidney disease: a prospective cohort study. Sci Rep. 2017;7:9374.
Ready to submit your research? Choose BMC and benefit from:

- fast, convenient online submission

- thorough peer review by experienced researchers in your field

- rapid publication on acceptance

- support for research data, including large and complex data types

- gold Open Access which fosters wider collaboration and increased citations

- maximum visibility for your research: over 100M website views per year

At BMC, research is always in progress.

Learn more biomedcentral.com/submissions 